\title{
Multi Objective Optimization of Cloud Computing Services for Consumers
}

\author{
Eli WEINTRAUB \\ Department of Industrial Engineering and Management \\ Afeka Tel Aviv Academic College of Engineering \\ Tel Aviv, Israel
}

\author{
Yuval COHEN \\ Department of Industrial Engineering and Management \\ Afeka Tel Aviv Academic College of Engineering \\ Tel Aviv, Israel
}

\begin{abstract}
This paper presents a novel multi objective model for optimizing the purchase decision of a cloud computing services customer. The providers are typically offering consumers cloud computing varying information systems services. The cloud services consist of different functionalities at varying costs, and varying reliability. So the customer's main objectives (based on the literature) are to maximize their utility, and minimize their costs and risks. Since utility cost and risks are different dimensions, the problem is essentially a multi-objective optimization problem. So far, previous research does not address the multi objective nature of the problem. This article deals with optimizing consumers' decision, but at the same time maintaining each of their objectives' considerations. An optimization model presented and illustrated. The article also demonstrates the advantages gained by the optimization model when implemented using the dynamic cloud architecture over the traditional cloud architecture.
\end{abstract}

Keywords-Cloud Computing; Security Risk; Software as a service; Platform as a service; Infrastructure as a service; Optimization; Cost; Utility

\section{INTRODUCTION}

There are several definitions for Cloud Computing (CC). In this work we use NISTs' definition [1] as an on-demand convenient remote access to a pool of computing resources managed by a CC service provider.

In the past, organizations managed their computing resources inside their geographical borders. In the last years more organization move their servers outside their firms' borders, to Service Providers (SP) who take responsibility of various computing activities managing the computing resources and facilitating the services. Doing so, organizations are facing new risks and problems which they have not met in the past. Reference [2] claims that organizations have to make changes in the production processes, defining new risk management procedures, and changing their IT management processes.

$\mathrm{CC}$ services are being used by four kinds of organizations: public, community, hybrid and private [3]. Public organizations locate their computing resources inside their geographic borders or outside it, at the cloud services providers' site, after considering issues of privacy, security, ease of production and financial. Community services are aimed at a group of consumers who have similar interests, buying resources from one external service provider. Hybrid services enable consumers using their internal resources in parallel to outside providers. Private customers, mostly locate resources at the providers' site. CC providers allocate their resources, which they supply to various consumers, trying to make a total safe separation of data and processes belonging to different organizations.

This article reviews the main advantages of using CC model and reviews the barriers and risks adopting the CC model. The information security issue is mentioned in literature as a barrier to $\mathrm{CC}$ adoption, and is an issue dealt largely in CC research [4].

Consumers' buying decisions of $\mathrm{CC}$ services are not simple. Providers are typically offering consumers cloud computing varying services, difficult for comparison. The services consist of different functionalities at varying costs, and varying reliability. So the customer's main objectives are maximization of their utility, and minimization their costs and risks. Since utility, cost and risks are different dimensions, the problem is essentially a multi-objective optimization problem. Published research does not address the multi objective nature of the problem. This article deals with optimizing consumers' decision, but at the same time maintaining each of their objectives' considerations. The article reviews the known models dealing with a single objective optimization decision. In this article, a novel multi-objective optimization model presented and illustrated. The article also demonstrates the advantages gained by the optimization model when implemented using the dynamic cloud architecture.

The article is organized as follows: Section II is an overview of the current $\mathrm{CC}$ architecture and the dynamic network architecture, which is used by the model. Section III reviews consumers' buying considerations. Section IV is an overview of cost optimization, Section V reviews utility optimization. Section VI reviews risk optimization. Section VII presents and illustrates the Multi Objective Optimization model proposed in this paper. Finally, section VIII concludes and suggests future possible research directions.

\section{Cloud Computing Architecture}

$\mathrm{CC}$ architecture consists of three layers: Infrastructure (IaaS), Platform (PaaS) and Software application (SaaS). Each layer is responsible for delivery of certain services for consumers. Each layer also fulfils the requests of the upper layers. A framework of the $\mathrm{CC}$ architecture is defined by [5], composed of three layers in parallel to functions supporting $\mathrm{CC}$ services. Figure I describes current CC architecture. 
Rectangles describe computing services. The organization buys all $\mathrm{CC}$ services from one SP.

The functions of each layer are as follows:

Infrastructure layer - This layer provides basic technologies as hardware, communication resources, operating systems and systems' utilities.

Platform layer - This layer operates on the top of the infrastructure layer, providing platform services such as development environments and business platforms.

Application layer - This layer operates on top of the platform and infrastructure layers, providing applications software and human interfaces used by the organizations' endusers and customers.

Service providers offer their services in bundles. A consumer buying a SaaS service will have to use the PaaS and IaaS services offered by the SP. A consumer wishing to buy a PaaS service will have to use also the providers' IaaS services. The bundling practice forbids consumers who wish to consume certain services from different SPs. According to [5], nowadays, certain providers use to run applications running on other providers' infrastructure, but the consumer is blind to this separation of platforms while buying his service from one single SP. The bundling practice limits free market forces from competing in this king of services, forcing customers pay for services they may buy from other providers in cheaper prices. For example, a consumer may buy a PaaS service from SP1, but the underlying IaaS service from a SP2, which sells the appropriate infrastructure service cheaper than SP1. According to [6], in the future, application will be designed including modularity which will enable running parts of the application on different SPs' platforms. Ref. [5] states that the cloud computing architecture is more modular compared to traditional hosting architectures, which might be a byproduct of the CC three layers' architecture. CC components are loosely coupled, thus enabling the development of modular applications which enable distribution the application among several SPs. Ref. [7] also claims that applications belonging to different layers will run on separate geographical locations. Ref. [8] claims that virtual machine hardware allows transfer of applications to other machines, provided by different IaaS providers. Ref. [9] suggests to make use of multiple clouds, achieving security targets.

This article continues the research direction proposed in [10] basing CC services on a dynamic business model. According to the dynamic model a consumer is able to buy certain SaaS services using SP1 resources and buy PaaS or IaaS services from other service providers. Implementation of the dynamic architecture needs technological standardization of the interfaces, which enables improved interoperability and connectivity of applications' components. Also, systems' building blocks should implement loose coupling principles. Following those design principles will enable connectivity among vertical and horizontal services, thus eliminating the bundling phenomena. References [10] [11] demonstrate the advantages achieved in aspects of consumers' cost and utility optimization, based on the dynamic architectural model. Figure II presents the dynamic CC architecture, describing consumers served by different providers for each layer and service. Arrows describe services supplied by underlying layers. Rectangles describe CC services. The business consumes its CC services from many SP's choosing the best combination of service providers.

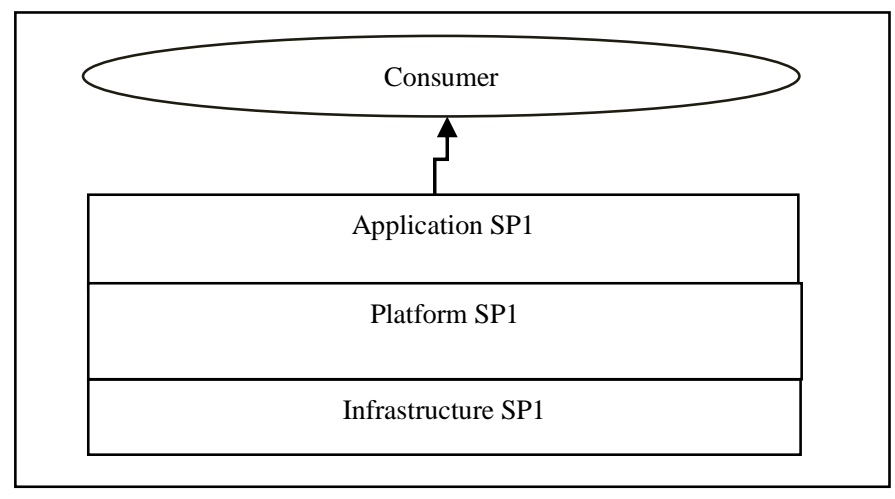

Fig. 1. Cloud Computing Current Architecture - one service provider

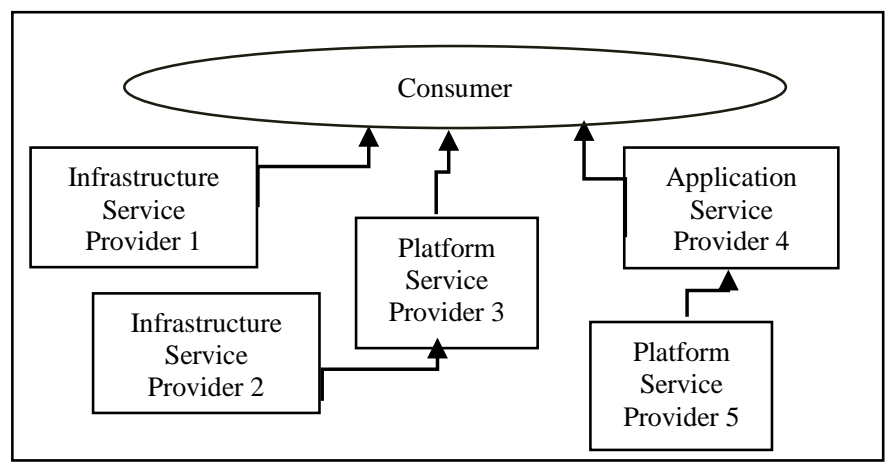

Fig. 2. Cloud Computing Dynamic Architecture

\section{BUYING CONSIDERATIONS}

Organizations use varying criteria for their $\mathrm{CC}$ buying decisions. There are organizations emphasizing costs, other emphasize risks while others consider the overall utility in their CC adoption decisions. Ref. [12] found that financial organizations regard $\mathrm{CC}$ a cost-effective technology which contributes to their capital efficiency. The researchers also found that financial organizations regard security as a barrier to $\mathrm{CC}$ adoption, among other risk factors.

Comparisons of pricing models of CC services is an issue researched largely, but variations among the structures of the pricing schemes puts major difficulties in coming to clear conclusions [14]. There are different viewpoints on the issue of CC costs. Ref. [15] found that organizations regard cost savings as the first adoption motivation, but the least researched issue, although research interests are rising.

Lack transparency of the resources supplied by service providers are regarded a key risk factor for organizations considering CC adoption. Several researchers studied the transparency issue. In one research, public cloud consumers got no permissions to view IT infrastructures, in other cases, consumers got partial views of resource consumption [16] [17]. Consumers wishing to make predictions concerning their future $\mathrm{CC}$ cost have difficulties because of the transparency issue, and lack of monitoring tools. According to [18] there is 
little research on the monitoring and prediction strategies in the $\mathrm{CC}$ domain. Researchers suggest handling the transparency issue by introducing pricing models presenting all components' prices of each service [19]. Other researchers state that currently, varying pricing models and large numbers of CC providers lead to complexities in the adoption decision process [20].

Cost and risk minimization in buying decisions lacks considerations of the vast advantages of CC model. Several organizations focus on $\mathrm{CC}$ utilities or a mix of expenses and utility considerations. Several organizations prefer to compare the utilities rather than expenses of risk adoption. In those cases, consumers face the same kind of difficulties stemming from the issue of insufficient transparency. Utility criteria selection might be complicated to measure and compare since providers offer different services having various functionalities, on un-standard scales. Various techniques have been suggested simulating consumer utility decisions. There are several techniques coping this purpose. Literature describes conjoint analysis a useful methodology, which enables coping with providers' selection issue.

To conclude, there is much research showing a large variance in usage of criteria lists used for $\mathrm{CC}$ adoption decisions. $\mathrm{CC}$ decisions involves complicated decisions with no standard scales assisting consumers in performing evaluations assisting management decisions. We categorize the decision factors to three main kinds: cost minimization, risk minimization, and utility maximization, each category consists of specific characteristics.

\section{COST OPTIMIZATION}

Literature describes two principal pricing models. The pay-per-use model is the popular model, and the second fixedprice model [21]. In the pay-per-use model consumers pay a fee according to the price of the resource, duration and volume consumed. Resources are IT components such as hardware, operating system, database, e-mail or enterprise application [22]. Volumes are specified as resource units such as processor seconds, disk or memory gigabytes, number of printed pages etc'. In the pay-per-use model consumers are not limited to the volume or duration they use, although some agreements limit volumes to a maximal amount above which the service stops. In the fixed-price model, the consumer pays for the resource consumed irrespective of the duration and volume. This model defines only the period (usually month or year) the consumer may use the service. In case the user does not use all the volume he planned to, he will pay the fee although he had not consumed it. Researchers state that the pay-per-use model is a better driver to free market competition and to efficient computing resources allocation in the $\mathrm{CC}$ market [23]. Researchers state that the pay-per-use model is the current CC market trend direction [24].

Researchers found several kinds of anomalies during consumers' decisions concerning choosing a costing model. Some consumers prefer to pay more for a fixed-price scheme for volumes they may not use [25]. Ref. [26] defined a pricing model called a bursting model, which balances consumers' varying demands to computing resources by switching resource workloads among consumers, offering consumers a stable quality of service. This model assists consumers solving dilemmas caused by reaching the maximal package capacity in cases of high workloads.

Researchers found biases of two kinds: irrational economic decisions preferring the pay-per-use model and the opposite irrational decision. Ref. [27] found that consumers are paying more in a fixed-price model for budget planning argumentations, and found cases of consumers choosing the pay-per-use model and actually paying more, for reasons of inability to predict future resource consumption. Ref [28] who studied consumers' pricing models also states that the fixedprice biased decisions, were influenced by budgetary argumentations, while the pay-per-use biased decisions were influenced by the productions' flexibility motivation.

Pricing biases stemming from providers' interests are described in research literature. Providers are mainly interested in marketing and strategic reasons. Providers differentiate users' pricing schemes, offering cheap prices, sometimes free of charge, or high service level agreements to consumers they are interested to attract or lock-in [28] [29]. Providers are customizing special software features to certain customers, which need also programming changes in consumers' software, thus causing them high switching costs when they are considering leaving to other providers [30].

Ref. [10] proposes a framework, which enables to compare different tariff tables of different SPs on one unified scale, thus optimizing costs. Nevertheless, that framework does not deal with other buying considerations such as risk and utility.

\section{UTILITY OPTIMIZATION}

There are several techniques enabling utility comparison of different services and products, such as Cluster Analysis and Multidimensional Scaling (MDS) [31]. Conjoint analysis is a methodology which enables to analyze buying trade-offs considerations among competing products [32]. The methodology makes use of a technique examining the characteristics of each product, simulating and predicting buyers' considerations while comparing different products. A study which used conjoint analysis methodology described in [33] found that the most influencing CC buying decisions' characteristics were quality of service and lock-in prevention. Researchers found that information security is a factor in CC adoption considerations [34]. Ref. [35] states that consumers are shifting from technological to service-oriented issues in their CC adoption considerations. In a survey [36], researchers found that the consumers mentioned six attribute levels: (1) providers' reputation, (2) required skills, (3) migration process, (4) pricing tariff, (5) cost compared to internal solution and (6) consumer support. Security is an adopting barrier to CC services [37]. Ref. [36] who used conjoint analysis, found that providers' reputation was the attribute with the highest relative importance of $26 \%$, migration process was the second with $21 \%$ importance. Cost has been found fourth having $16 \%$ relative importance. Researchers who studied service attributes influencing on CC adoption, found seven groups of attributes: Monetary payoff, usability, flexibility, trademark, added value, connectivity and customers' support [38]. 
To conclude, there has not been found one single list of utility attributes, nor one agreed methodology for utility comparisons. Ref. [39] [11] describe a methodology which enables utility attributes comparison for consumers in the CC dynamic environment, but lacking cost and risk considerations.

\section{RISK OPTIMIZATION}

Risk assessment in the CC domain is an issue dealt intensively in literature [40] [41]. Researchers state that security risks are among the biggest obstacles to adoption cloud services [9].

This article focuses on security risks since this risk category is a major inhibitor of CC adoption, without limiting generality of the proposed model. Security risks as a subgroup of the outsourcing issue are a complex research area, which researchers still are not able to fully capture it's complex nature [42]. Ref. [43] States that managing security risks is getting more complex, and many publications include proposals targeting the various cloud security threats.

Cloud security covers several categories. Ref. [44] surveyed the research publications on cloud security issues, identified the basic concepts underlying vulnerabilities and threats, and classified them as follows: virtualization elements, multi-tenancy, cloud platform and software, data outsourcing, data storage security and standardization and trust. Ref. [45] also categorized security risks to three kinds: Multiple Users, Minimal Control and Single Point of control. Ref. [43] presents a method to assess security risks and a set of steps to identify and assess security risks. Accordingly, risks are categorized to Six-View Perspectives: Threat view, Resource View, Process View, Risk Assessment View, Management View, and Legal View. Ref. [39] presents a security risk assessment model based on ISACA's framework defined [46]. The framework is designed to present a practical guidance for IT and business professionals concerning the decision to move to the cloud. The guide provides checklists outlining the security factors considered when evaluating the cloud as a potential solution.

Ref. [39] proposes a model, assisting consumer in assessing risks, but does not handle decision factors of cost and utility maximization.

To summarize, there is no one integrative model enabling decision support for managements who wish to compare and evaluate all CC attributes, naming costs, risks and utility.

Next, we present our Multi Objective Optimization model.

\section{The Multi Objective Optimization Model}

This section analyzes the $\mathrm{CC}$ consumer choice as a multidimensional model and propose a structured approach to eliminate alternatives and choose the best option.

There are three main objectives that a CC user seeks to optimize when choosing service provider:

1) Maximal utility

2) Minimal cost

3) Minimal risk
The different dimensions of these objectives are an obstacle in the way to form a simple model for decision making (mainly choice of service provider and a bundle of services). While translating everything to money is possible it is typically subjective and far from accurate. The same could be said about a fitness function.

We start optimization computations using the original data of each dimension (naming cost, utility and risk) which was computed according to its specific characteristics. Cost computed according [10], utility computed according to [11], and risk scores computed according to [39].

We now present the multi objective optimization model in two business models. First the case of bundled services of all three layers in which an organization buys all CC services from one single service provider, implemented on the current $\mathrm{CC}$ architecture as described in Fig. I. Second, the business model of a free market - Choosing the best provider per layer, among all SPs. This business model is implemented on the dynamic $\mathrm{CC}$ architecture as described in Fig. II.

\section{- The case of bundled services of all three layers}

$\mathrm{CC}$ has three fundamental layers (IaaS, PaaS, SaaS), and the SPs traditionally try to bundle their services in all the layers so as to bound the consumer to them in all the three layers. In this case, the customer needs to consider and choose only one of the various potential SPs. Suppose we have $n$ SPs to compare: each one offers a bundle of services that contributes a utility to the consumer, with associated risks, for a given cost. Therefore, comparing $n$ SPs is done by comparing their $n$ three-dimensional points. It is therefore essential that we develop the mechanism to deal with such three dimensional comparisons.

On the other hand, if we assume the free market forces will enable purchasing services for each layer independently from the other layer, we would have to repeat the choice between $n_{i}$ providers three times $(\mathrm{i}=1,2,3)$ : each layer comparison is based on the number of SPs providing that layer- each one is a three dimensional model.

The proposed method is based on rescaling each score to a common scale, which enable a common graphical representation (the original values are retained, and could be used if necessary). This approach retains three separate dimensions for the comparison (unlike translating the objective to one fitness function, or to monetary value).

The method works as follows: for each dimension, we rescale the best performance to be 10 , and the least performance to be 5 . The other scores are then interpolated in that range. We then rule out suppliers having worst performance in any dimension. This process of ruling out or eliminating SPs continues until the last one is left.

The following example illustrates the suggested techniques. Table 1 includes the original values of utility, cost and risk score for five SPs. Tables 2,3 normalize the original values to one common scale. Fig. III presents graphically the normalized objective values. 
TABLE I. ORIGINAL DATA

\begin{tabular}{|l|l|l|l|}
\hline Supplier & Annual Utility & Annual Cost & Annual Risk \\
\hline SP1 & 8 & $\$ 50,000$ & 12 \\
\hline SP2 & 7 & $\$ 60,000$ & 8 \\
\hline SP3 & 10 & $\$ 70,000$ & 15 \\
\hline SP4 & 9 & $\$ 50,000$ & 10 \\
\hline SP5 & 8 & $\$ 40,000$ & 9 \\
\hline
\end{tabular}

TABLE II. COMMON SCALE COMPUTATIONS

\begin{tabular}{|l|l|l|l|}
\hline Supplier: & $\begin{array}{l}\text { Annual } \\
\text { Utility }\end{array}$ & Annual Cost & Annual Risk \\
\hline Optimal & 10 & 40,000 & 8 \\
\hline Least Optimal & 7 & 70,000 & 15 \\
\hline
\end{tabular}

\begin{tabular}{|l|l|l|l|}
\hline Range & 3 & 30,000 & 7 \\
\hline New max & 10 & 10 & 10 \\
\hline New min & 5 & 5 & 5 \\
\hline New range scale & $3 / 5$ & $30,000 / 5=6,000$ & $7 / 5$ \\
\hline
\end{tabular}

TABLE III. COMMON SCALE

\begin{tabular}{|l|l|l|l|}
\hline Supplier & Annual Utility & Annual Cost & Annual Risk \\
\hline SP1 & 6.67 & 8.33 & 7.14 \\
\hline SP2 & 5.00 & 6.67 & 10.00 \\
\hline SP3 & 10.00 & 5.00 & 5.00 \\
\hline SP4 & 8.33 & 8.33 & 8.57 \\
\hline SP5 & 6.67 & 10.00 & 9.29 \\
\hline
\end{tabular}

\section{Multi-Objective Comparison}

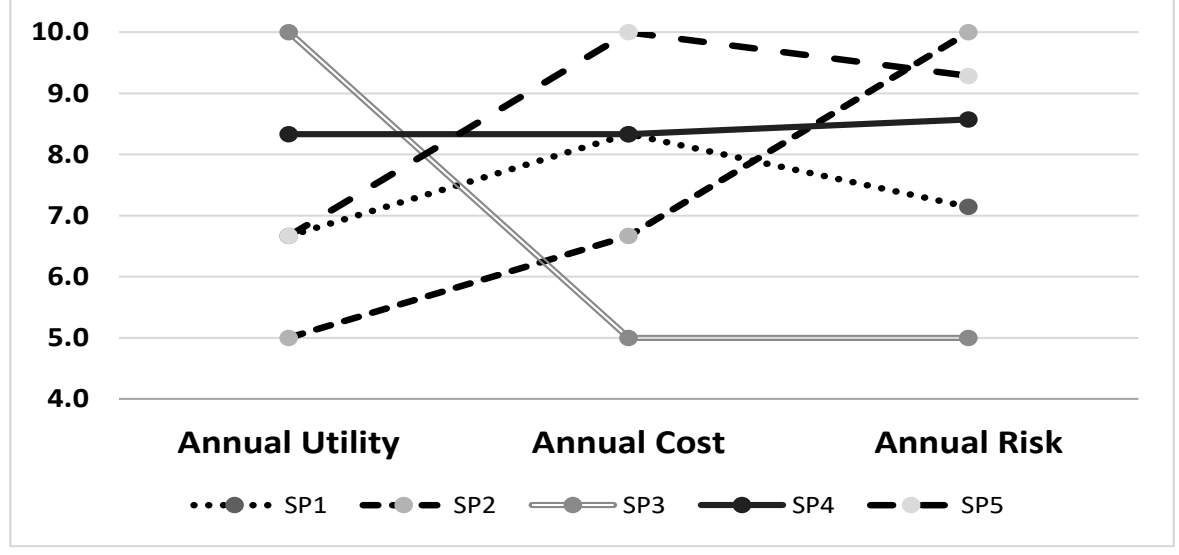

Fig. 3. Graphical representation of the objective dimensions of 5 SPs

It is clear from Fig. III above that:

In this case SP3 is worse in terms of Cost and Risk, and therefore is eliminated.

SP2 is worse in terms of Utility, and therefore is eliminated. IV.

The remaining suppliers (1,4 and 5) are depicted in Fig.

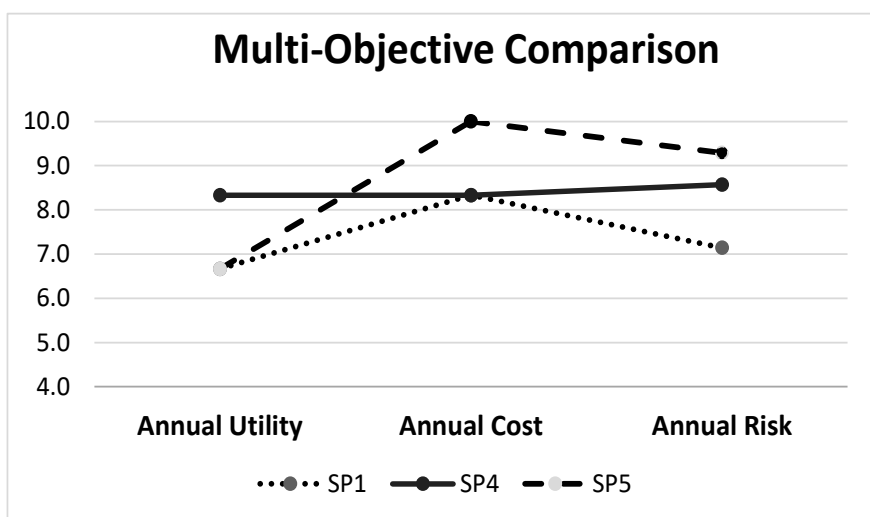

Fig. 4. Graphical representation of the objective dimensions of remaining SPs
From Fig. IV it is clear that SP1 form the lower envelop and is eliminated. Then for the remaining SP4 and SP5: SP4 has two minimal points while SP5 only one, so SP5 remains the best option.

Another approach would be using the original numbers of each remaining supplier (as in Table 4).

TABLE IV. THE LAST REMAINING SPS

\begin{tabular}{|l|l|l|l|}
\hline Supplier & Annual Utility & Annual Cost & Annual Risk \\
\hline SP4 & 9 & $\$ 50,000$ & 10 \\
\hline SP5 & 8 & $\$ 40,000$ & 9 \\
\hline
\end{tabular}

So the final tradeoff is between a unit of utility vs. $\$ 10,000$ plus a unit of risk.

Here a subjective decision could be taken, based on the preference of the individual.

Another possibility is to design simple decision rule to choose between SP4 and SP5. For example, if each dimension has the same importance, the scales in table 2 could be used:

$3 / 5$ Utility $=\$ 6,000=7 / 5$ Risk. So 1 Utility $=\$ 10,000=$ $7 / 3$ Risk, and SP5 is chosen over SP4 since: 1 Utility $<\$$ $10,000+1$ Risk 


\section{- The case of a free market -Choosing provider per layer}

The practice of SPs to bundle their services in all three layers into one offering dictate a choice and a contract with a single SP. In contrast to the bundled services, free market forces should enable customers acquire services in each layer, independently from the other layers. In the long run we would have to repeat the choice between $n_{i}$ providers for each layer that is three times $(\mathrm{i}=1,2,3)$ : each layer comparison is based on the number of SPs providing that layer- each combination of a layer and SP is still a three dimensional point. Table 5 describes the break-down of Table 1 into the three layers.

TABle V. Original Data of TABle 1 Detailed by layer

\begin{tabular}{|l|l|l|l|l|l|l|l|l|l|}
\hline Supplier & \multicolumn{3}{|l}{ Annual Utility } & \multicolumn{4}{l|}{ Annual Cost } & \multicolumn{2}{l|}{ Annual Risk } \\
\hline & IaaS & PaaS & SaaS & IaaS & PaaS & SaaS & IaaS & PaaS & SaaS \\
\hline SP1 & 2 & 3 & 3 & $\$ 15,000$ & $\$ 15,000$ & $\$ 20,000$ & 4 & 4 & 4 \\
\hline SP2 & 2 & 2 & 3 & $\$ 15,000$ & $\$ 20,000$ & $\$ 25,000$ & 2 & 3 & 3 \\
\hline SP3 & 3 & 3 & 4 & $\$ 15,000$ & $\$ 25,000$ & $\$ 30,000$ & 5 & 5 & 5 \\
\hline SP4 & 3 & 3 & 3 & $\$ 20,000$ & $\$ 15,000$ & $\$ 15,000$ & 3 & 4 & 4 \\
\hline SP5 & 3 & 3 & 2 & $\$ 10,000$ & $\$ 15,000$ & $\$ 15,000$ & 3 & 3 \\
\hline
\end{tabular}

Table 5 is conveniently broken down into three layers as described in tables 6, 7, and 8. Tables 6,7 present the detailed computations of IaaS optimization. Fig. V

Finding the best IaaS SP

TABLE VI. ORIGINAL IAAS DATA By LAYER (FROM TABLE 5)

\begin{tabular}{|l|l|l|l|}
\hline Supplier & Annual Utility & Annual Cost & Annual Risk \\
\hline & IaaS & IaaS & IaaS \\
\hline SP1 & 2 & $\$ 15,000$ & 4 \\
\hline SP2 & 2 & $\$ 15,000$ & 2 \\
\hline SP3 & 3 & $\$ 15,000$ & 5 \\
\hline SP4 & 3 & $\$ 20,000$ & 3 \\
\hline SP5 & 3 & $\$ 10,000$ & 3 \\
\hline
\end{tabular}

TABLE VII. IAAS COMMON SCALE

\begin{tabular}{|l|l|l|l|}
\hline Supplier & Annual Utility & Annual Cost & Annual Risk \\
\hline SP1 & 5.0 & 7.5 & 6.7 \\
\hline SP2 & 5.0 & 7.5 & 10.0 \\
\hline SP3 & 10.0 & 7.5 & 5.0 \\
\hline SP4 & 10.0 & 5.0 & 8.3 \\
\hline SP5 & 10.0 & 10.0 & 8.3 \\
\hline
\end{tabular}

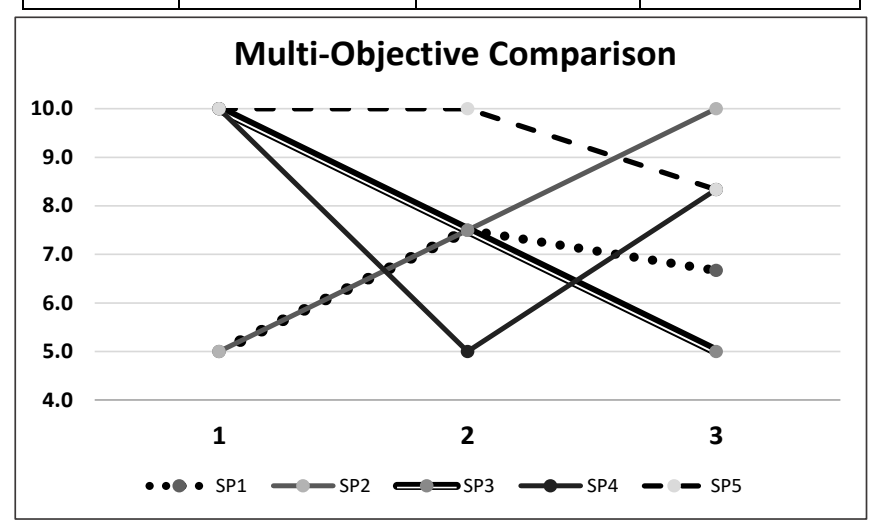

Fig. 5. IaaS SPs Comparison on a Common Scale

It is easy to see in Fig. V above that SP1 and SP2 have minimal utility point, SP3 has maximal risk point and SP4 has maximum cost point. Thus, only SP5 is not eliminated, and is the best IaaS choice.

This procedure repeats twice more for the PaaS and SaaS layers and yields the following. Tables 8, 9, 10, 11 and Fig.
VI, Fig. VII follow similar computations for PaaS and SaaS layers.

\section{Finding the best PaaS SP}

TABle VIII. Original PaAS Data by Layer (From table 5)

\begin{tabular}{|l|l|l|l|}
\hline Supplier & Annual Utility & Annual Cost & Annual Risk \\
\hline & PaaS & PaaS & PaaS \\
\hline SP1 & 3 & $\$ 15,000$ & 4 \\
\hline SP2 & 2 & $\$ 20,000$ & 3 \\
\hline SP3 & 3 & $\$ 25,000$ & 5 \\
\hline SP4 & 3 & $\$ 15,000$ & 4 \\
\hline SP5 & 3 & $\$ 15,000$ & 3 \\
\hline
\end{tabular}

TABLE IX. PAAS COMMON SCALE

\begin{tabular}{|l|l|l|l|}
\hline Supplier & Annual Utility & Annual Cost & Annual Risk \\
\hline SP1 & 10 & 10 & 7.5 \\
\hline SP2 & 5 & 7.5 & 10 \\
\hline SP3 & 10 & 5 & 5 \\
\hline SP4 & 10 & 10 & 7.5 \\
\hline SP5 & 10 & 10 & 10 \\
\hline
\end{tabular}

\section{Multi-Objective Comparison}

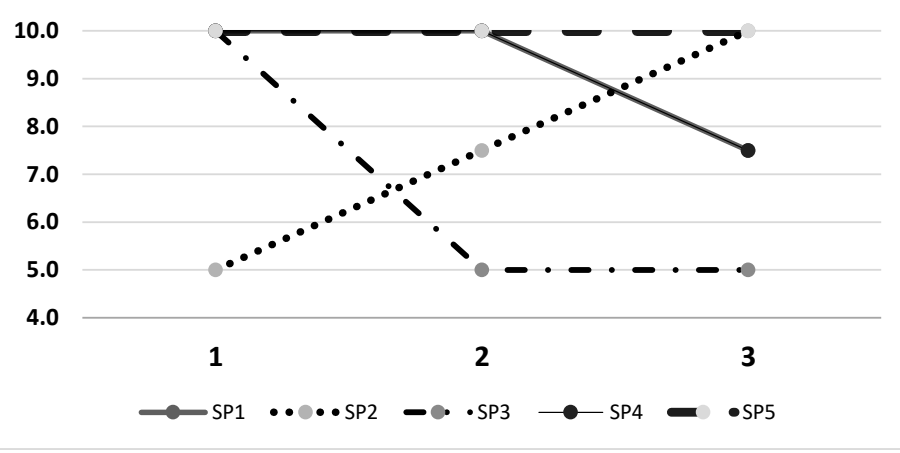

Fig. 6. PaaS SPs Comparison on a Common Scale

In this case, it is easy to see that SP5 dominates all other SPs and is the preferred choice.

Finding the best SaaS SP 
TABLE X. ORIGINAL SAAS DATA By LAYER (FROM TABLE 5)

\begin{tabular}{|l|l|l|l|}
\hline Supplier & Annual Utility & Annual Cost & Annual Risk \\
\hline & SaaS & SaaS & SaaS \\
\hline SP1 & 3 & $\$ 20,000$ & 4 \\
\hline SP2 & 3 & $\$ 25,000$ & 3 \\
\hline SP3 & 4 & $\$ 30,000$ & 5 \\
\hline SP4 & 3 & $\$ 15,000$ & 4 \\
\hline SP5 & 2 & $\$ 15,000$ & 3 \\
\hline
\end{tabular}

TABLE XI. SAAS COMMON SCALE

\begin{tabular}{|l|l|l|l|}
\hline Supplier & Annual Utility & Annual Cost & Annual Risk \\
\hline SP1 & 7.5 & 8.3 & 7.5 \\
\hline SP2 & 7.5 & 6.7 & 10.0 \\
\hline SP3 & 10.0 & 5.0 & 5.0 \\
\hline SP4 & 7.5 & 10.0 & 7.5 \\
\hline SP5 & 5.0 & 10.0 & 10.0 \\
\hline
\end{tabular}

TABLE XII. ORIGINAL DATA FOR OPTIMAL CHOICE FOR EACH LAYER: IAAS: SP5; PAAS - SP5; SAAS - SP4

\begin{tabular}{|c|c|c|c|c|c|c|c|c|c|}
\hline Supplier & \multicolumn{3}{|c|}{ Annual Utility } & \multicolumn{3}{|c|}{ Annual Cost } & \multicolumn{3}{|c|}{ Annual Risk } \\
\hline & IaaS & PaaS & SaaS & IaaS & $\mathrm{PaaS}$ & SaaS & IaaS & $\mathrm{PaaS}$ & SaaS \\
\hline SP4 & & & 3 & & & $\$ 15,000$ & & & 4 \\
\hline SP5 & 3 & 3 & & $\$ 10,000$ & $\$ 15,000$ & & 3 & 3 & \\
\hline Total & 3 & 3 & 3 & $\$ 10,000$ & $\$ 15,000$ & $\$ 15,000$ & 3 & 3 & 4 \\
\hline Total Utility & & & 9 & Total Ce & & $\$ 40,000$ & Tota & & 10 \\
\hline
\end{tabular}

Comparing to the service bundling case where pure SP5 was chosen we could see that optimizing each of the three layers we get more utility at additional risk, as presented in Table 13.

TABLE XIII. Multi OBJeCTIVE COMPARISON

\begin{tabular}{|l|l|l|l|}
\hline Supplier & Annual Utility & Annual Cost & Annual Risk \\
\hline SP5 & $8<9$ & $\$ 40,000$ (same) & $9<10$ \\
\hline
\end{tabular}

In general, optimizing each of the three layers is bound to give either comparable or better results than the choice of a single SP.

\section{CONCLUSIONS}

This paper examines the acquisition of $\mathrm{CC}$ services from the perspective of $\mathrm{CC}$ customers. While minimizing cost is easy and popular objective for the customers, it captures only a part of the customer's considerations. Maximizing the utility of the customer could be a more inclusive alternative, but since the conversion of money to utility is a tricky business, cost (which could be part of the utility function) is better off as a separate objective. Minimizing risk is a third consideration which is not well suited for conversion to either utility or cost, and thus is a third major objective. Thus, the $\mathrm{CC}$ consumer is

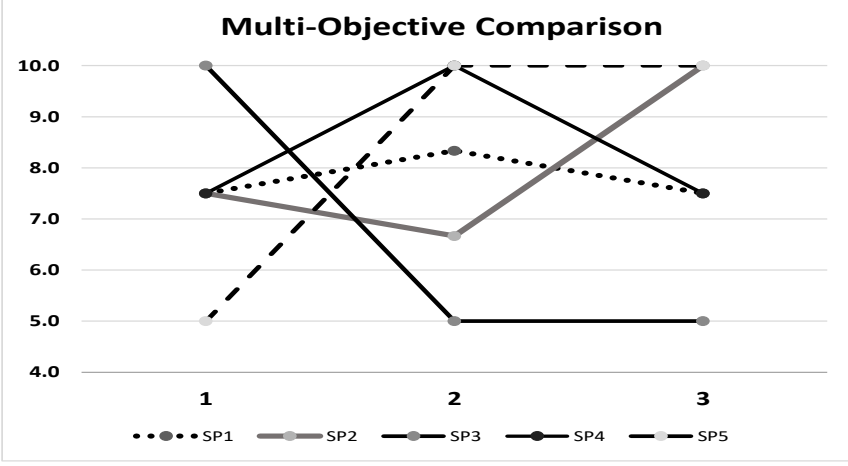

Fig. 7. SaaS SPs Comparison on a Common Scale

It could be inferred from Fig. VII that SP5 should be eliminated due to minimal Utility. SP3 should be eliminated due to maximal risk and cost. Then, SP2 should be eliminated due to minimal remaining value of utility and maximal remaining cost. The remaining alternatives are SP1 and SP4. Since SP4 has lower cost than SP1, and have identical utility and risk. Thus, SP4 is dominating SP1 in SaaS and is the chosen alternative.

Synthesizing the choices at each layer we have: IaaS: SP5; PaaS - SP5; SaaS - SP4. Table 12 summarizes this optimal choice. simultaneously maximizing its utility and minimizing the cost and the risks. Accordingly, this paper presents a multiobjective optimization approach.

While much research has been conducted on CC consumers' decisions (for assessing and optimizing providers' services), current models enable optimizing each dimension separately (cost, utility and risk) on its own scale. Since we did not find in the literature any multi objective models optimizing consumer $\mathrm{CC}$ service acquisition. Thus, for the best of our knowledge this is the first time that multi-objective optimization is applied to CC service acquisition.

The proposed model makes use of the dynamic CC architecture, which enables consumers to buy services from several SPs. each one offering services of different layers. We have shown that basing on the dynamic $\mathrm{CC}$ architecture organizations can achieve superior advantages relative to the current CC architecture.

Further research is possible in several directions. First, defining a model performing a sensitivity analysis for changes in each dimension. Second, studying ways which assist consumers in assigning their importance weights to their decisions' dimension, which are currently performed subjectively and intuitively. Third, studying ways assisting organizations assess future values of decisions dimensions. 
Currently, organizations assess their future $\mathrm{CC}$ costs for making their $\mathrm{CC}$ adoption decisions (also their utility and risk scores) according to general knowledge, not relying on objective quantitative measures, sometimes irrelevant to their specific current configuration. It is hoped that this paper will contribute to more structured and quantitatively based decisions.

\section{REFERENCES}

[1] P. Mell, and T. Grance, "The NIST definition of cloud computing", National Institute of Standards and Technology, NIST, Vol. 53 No. 6, p. 50, 2009.

[2] T. Pueschel, A. Anandasivam, S. Buschek, and D. Neumann, "Making money with clouds: Revenue optimization through automated policy decisions". ECIS - European Conference on Information Systems 17, 2009.

[3] C. Weinhardt, B. Blau, and J. Stößer, "Cloud Computing - A Classification, Business Models, and Research Directions". Business \& Information Systems Engineering, May 2009.

[4] A. Gill, D. Banker, and P. Seltsika, "Moving Forward: Emerging Themes in Financial Services Technologies Adoption", Communications of the Association for Information Systems: Vol. 36, Article 12, 2015.

[5] Q. Zhang, L. Cheng, and R. Bautaba, "Cloud computing: State-of-the-art and Research challenges", J Internet Serv Appl 1:7-18, 2010.

[6] F. Paraiso, N. Haderer, P. Merle, R. Rouvoy, and L. Seinturier, "A Federated Multi-Cloud PaaS Infrastructure", IEEE Fifth International Conference on Cloud Computing, 2012.

[7] A. Velte, R. Elsenpeter, and T. J. Velte, "Cloud Computing: A practical approach". Tata McGraw-Hill Education Pvt. Ltd, 2009.

[8] U. Z. Rehman, F. K. Hussain, and O. K. Hussain, "Towards MultiCriteria Cloud Service Selection", Fifth International Conference on Innovative Mobile and Internet Services in Ubiquitous Computing, 2011.

[9] J. Bohli, N. Gruschka, M. Jensen, L.L. Iacono, and N. Marnau, "Security and Privacy-Enhancing Multi cloud Architectures", IEEE Transactions on Dependable and Secure Computing, Vol. 10, No' 4, 2013.

[10] E. Weintraub and Y. Cohen, "Cost Optimization of Cloud Computing Services in a Networked Environment", (IJACSA) International Journal of Advanced Computer Science and Applications ,Vol. 6, No. 4, pp. 148-157, 2015.

[11] E. Weintraub and Y. Cohen, "Optimizing User's Utility from Cloud Computing Services in a Networked Environment", (IJACSA) International Journal of Advanced Computer Science and Applications, Vol. 6, No. 10, pp. 153-163, 2015.

[12] A. Gill, D. Banker, P. Seltsika, "Moving Forward: Emerging Themes in Financial Services Technologies Adoption", Communications of the Association for Information Systems: Vol. 36, Article 12, 2015.

[13] Z. Chen, F. Han, J. Cao, X. Jiang, S. Chen, 'Cloud Computing-Based Forensic Analysis for Collaborative Network Security Management System', Tsinghua science and technology, Vol 18/1, 2/ 2013.

[14] L. Yung-Ming, C. Chia-Ling, "Analyzing The Pricing Models For Outsourcing Computing Services". PACIS Proceedings, 2012.

[15] H. Yang, M. Tale, "A Descriptive Literature Review and Classification of Cloud Computing Research". Communications of the Association for Information Systems: Vol. 31, Article 2, 2012.

[16] M. Walterbusch, B. Martens, F. Teuteberg, "Evaluating cloud computing services from a total cost of ownership perspective". Management Research Review Vol. 36 No. 6, pp. 613-638, 2013.

[17] S. El Kihal, C. Schlereth, B. Skiera, "Price comparison for Infrastructure-as-a-Service". In: ECIS Proceedings, 2012.

[18] S. J. Ward, A. Barker, "Observing the clouds: a survey and taxonomy of cloud monitoring". Journal of Cloud Computing, 3:24, 2014.

[19] B. Blau, D. Neumann, C. Weinhardt, W. Michalk, "Provisioning of service mashup topologies", In: Proceedings of the 16th European conference on information systems, Galway, 2008.
[20] U. Z. Rehman, F. K. Hussain, O. K. Hussain, "Towards Multi-Criteria Cloud Service Selection", Fifth International Conference on Innovative Mobile and Internet Services in Ubiquitous Computing, 2011.

[21] M. Al-Roomi, S. Al-Ebrahim, S. Buqrais, I. Ahmad, "Cloud Computing Pricing Models: A Survey". International Journal of Grid and Distributed Computing: Vol 6. No 5, 2013.

[22] G. Bitran, R. Caldentey, "An overview of pricing models for revenue management", Manufacturing \& Service Operations Management 5(3):203-229, 2003.

[23] K. Lai, "Markets are dead long live markets", In: SIGecom Exchanges 5(4): pp 1-10, 2005.

[24] C. Weinhardt, B. Blau, J. Stößer, "Cloud Computing - A Classification, Business Models, and Research Directions". Business \& Information Systems Engineering 05/2009.

[25] T. Pueschel, A. Anandasivam, S. Buschek, D. Neumann, "Making money with clouds: Revenue optimization through automated policy decisions". ECIS - European Conference on Information Systems 17, 2009.

[26] M. Lilienthal, "A Decision Support Model for Cloud Bursting", Business \& Information Systems Engineering 2013.

[27] M. Walterbusch, B. Martens, F. Teuteberg, "Evaluating cloud computing services from a total cost of ownership perspective", Management Research Review Vol. 36 No. 6, pp. 613-638, 2013.

[28] P. Koehler, A. Anandasivam, M. Dan, C. Weinhardt, "Customer heterogeneity and tariff biases in cloud computing", Thirty First International Conference on Information Systems, St. Louis, ICIS proceedings, 2010

[29] J. K. MacKie-Mason, H. R. Varian, "Pricing Congestible Network Resources". IEEE Journal on Selected Areas in Communications 13, number 7, 1995.

[30] H. R. Varian, "Economics of Information Technology". Working Paper, 2003.

[31] P. Koehler, A. Anandasivam, and A. Dan, "Cloud services from a consumer perspective", AMCIS 2010 Proceedings, 2010.

[32] P. E. Green, A. M. Krieger, and Y. J. Wind, "Thirty Years of Conjoint Analysis: Reflections and Prospects". Interfaces Vol. 31, No.3, 2001.

[33] M. A. Armbrust, R.Fox, A.J. Griffith, R. Katz, A. Konwinski, G. Lee, D. Patterson, A. Rabkin, I. Stoica, and M. Zaharia., "Above the Clouds: A Berkeley View of Cloud Computing". Technical Report, Berkeley: CA, 2009.

[34] Z. Chen, F. Han, J. Cao, X. Jiang, and S. Chen, "Cloud ComputingBased Forensic Analysis for Collaborative Network Security Management System". Tsinghua science and technology, Vol 18, No. (1, 2), 2013.

[35] W .Venters, and E.A.Whitley, "A critical review of cloud computing: researching desires and realities", Journal of Information Technology, Vol. 27, No.3, 2012.

[36] P. Koehler, A. Anandasivam, M. Dan, and C. Weinhardt, "Customer heterogeneity and tariff biases in cloud computing". Thirty First International Conference on Information Systems, St. Louis, ICIS proceedings, 2010.

[37] R. Weiber, and D. Mühlhaus, "Auswahl von Eigenschaften und Ausprägungen bei der Conjointanalyse". In "Conjointanalyse", by D. Baier and M. Brusch, Heidelberg: Springer, 2009.

[38] K. Bogataj, A. Pucihar, "Business Model Factors Influencing Cloud Computing Adoption: Differences in Opinion", BLED Conference Proceedings, Bled:Slovenia, 2013.

[39] E. Weintraub, Y. Cohen, "Security Risk Assessment of Cloud Computing Services in a Networked Environment", International Journal of Advanced Computer Science and Applications (IJACSA), 7, (11), 2016.

[40] R. Latif, H. Abbas, S. Assar, \& Q. Ali, "Cloud computing risk assessment: a systematic literature review". In Future Information Technology, Springer Berlin Heidelberg, 2014.

[41] E. Furuncu, \& I. Sogukpinar, "Scalable risk assessment method for cloud computing using game theory", (CCRAM). Computer Standards \& Interfaces, 38, 2015. 
[42] T. Ackermann, T. Widjaja, A. Benlian, and P. Buzmann, "Percieved IT Security Risks of Cloud Computing: Conceptualization and Scale Development", Thirty Third International Conference on Information Systems, Orlando USA, 2012.

[43] S. B. Yadav, and D. Tianxi, "A Comprehensive Method to Assess Work System Security Risk," Communications of the Association for Information Systems: Vol. 34, Article 8, 2014.
[44] D. A. B. Fernandes, L. F. B. Soares, J. V. Gomes, M. M Freire and P. R. M. Inácio, "Security issues in cloud environments: a survey", Int. J. Inf. Secur. 13:113-170, 2014.

[45] B. Mansukhani and T. A. Zia, "The Security Challemges and Countermeasures of Virtual Cloud", Australian Information Security Management Confference, 2012.

[46] ISACA, "Security Considerations for Cloud Computing", USA, 2012. 